\title{
Techno-Economic Evaluation of Regulation Service from SEVs in Smart MG System
}

\author{
Amira Nisar Siddiqui ${ }^{1}$ (D) Mini S. Thomas ${ }^{1}$
}

Received: 3 August 2016 / Accepted: 6 October 2016 / Published online: 4 November 2016

(C) Springer Science+Business Media Singapore 2016

\begin{abstract}
A techno-economic evaluation of regulation service of microgrid system comprising renewable energy resources and electric vehicles has been done in this paper. $\mathrm{EV}$ operational strategy for MG regulation is developed by incorporating a vehicle controller which enables vehicle to grid or grid to vehicle mode operation, while plugged into the power distribution circuit. The functionality of grid integration of electric vehicle with vehicle to grid or grid to vehicle operation makes it a smart electric vehicle, suitable for operation in smart microgrid environment. The technoeconomic analysis is based on simulation results obtained from a microgrid test system operated with varying power generation and frequency regulation being provided by two different microgrid resources i.e., conventional battery storage system and proposed smart electric vehicles. The cost for providing frequency regulation using battery storage system and grid integration of vehicle is calculated and compared to find microgrid optimal operation option. The comparison of two costs reveals that smart electric vehicles have considerable economic potential for microgrid regulation service and hence provide better utilization of resources for optimal operation.
\end{abstract}

Keywords Battery storage system - Capacity cost - Cost of regulation-up · Energy cost - Smart electric vehicle .

Regulation services and vehicle to grid mode

Amira Nisar Siddiqui and Mini S. Thomas, Senior Member, IEEE

Amira Nisar Siddiqui amiranisar@gmail.com

1 Jamia Millia Islamia, New Delhi, India

\section{Introduction}

ELECTRIC power system has been undergoing evolutionary changes in response to the stringent requirements of power quality, reliability, improved operational efficiency, environmental compliance and energy conservation. Recent focus of power industries is to develop smart grids for improved power distribution system and also to upgrade conventional grids with smart grid technologies. A smart grid may be defined as the electrical power system with advanced electrical infrastructure, intelligent communication and control network integrated with smart electrical appliances and smart electric vehicles (SEVs) [1, 2]. Microgrids (MGs) are proving to be more promising, operating at low voltage, with distributed energy resources (DERs), storage devices and local loads to commensurate these profound changes [3, 4]. Microgrid is a localized grouping of electric power resources and loads that normally operate connected and synchronized with the traditional centralized grid (macrogrid), but can disconnect and function autonomously as physical and/or economic conditions dictate. More simply microgrid can be defined as a subset of macrogrid. A number of recent research work related to design, control and operation [5-7] of microgrids can be found in literature however attention towards the economic issues associated to the microgrid design and operation is less. Microgrid generally comprises of renewable power generation like solar photovoltaic (PV) generator or wind turbine but their power output is intermittent owing to the dependence on natural factors like irradiance and wind speed due to which these generators generally require storage batteries to maintain power balance between generation and load demand. Batteries also play important role in frequency regulation due to their quick response and two-way power transfer capability $[8,9]$. Non-renewable resources 
in a microgrid may comprise of diesel generators or micro gas turbines. The operation and maintenance cost of these distributed energy resources alongwith expensive battery storage systems (BSS) increases the overall operational cost of microgrid. Som et al. [10] suggest that electricity cost per unit in microgrid system comprising biomass gassifier, solar photovoltaic generator and battery storage system and for microgrid system with fuel cell generator, solar photovoltaic generator and battery storage system comes out to be US\$ 0.278 and US\$ 0.304 respectively. The electricity generation within microgrid has several advantages like reliability, no-transmission losses, less carbon emissions, etc. but cost per unit is higher as compared to the main grid. Thus there is a need to device techniques to make microgrid operation economical, to enhance the benefits. Seon-Ju Ahn et al. [11] presented an optimization technique to minimize the fuel cost from grid connected operation to islanding of a microgrid system. An economic dispatch problem is solved using direct search method with constraints formulated for fixed-droop and adjustable droop principle. Their method provided a precise solution for economic dispatch in conventional microgrid system. The work presented in our paper is related to the economics of advanced smart MG systems which involve smart electric vehicles.

In recent years there have been major improvements in electric vehicle technologies and increase in their deployment in mass market. Majority of the previous work regarding grid integration of electric vehicle focuses on their coordinated charging technologies for energy management and optimised operation [12-14]. Evaluation of widespread use of electric vehicle in a smart grid by analyzing adequacy indices and security perspective is done in [15], leading to the results that the managed charging and vehicle to grid scenarios can be used to improve the smart grid operation. This is due to the reason that electric vehicles act as storage system while not in movement. Hence it will be interesting to propose the grid integration of vehicle for further smart grid services like regulation service as presented in our paper here.

Work has also been done to analyse the impact of electric vehicle integration on distribution circuits [16-18]. Technical description and comparison of centralised and decentralised grid integration of vehicle (GIV) mechanisms for providing regulation service is described and compared in [19]. For centralised GIV mechanism, quadratic optimization problem is solved to find the individual regulation power and preferred operation point (POP). Decentralised GIV mechanism is agent-based system in which electric vehicle agent autonomously calculates its regulation power using POP calculation method. Authors in [20] showed that microgrid system performance improved considerably when electric vehicles were used to help in frequency control and also that a large number of electric vehicles can be integrated while adopting advanced centralized electric vehicle charging control strategies without the need to proceed for grid reinforcement. Practical demonstration of vehicle to grid power providing real-time frequency regulation from electric car is reported in [21]. While the literature review showed that the analysis on grid integration of electric vehicle is quite extensive, there is still a need to analyse its impact with respect to microgrid paradigm.

Microgrid systems do not have conventional automatic generation control and spinning reserves, thus the task of providing regulation services for a microgrid becomes more challenging. Battery storage system provides a technical solution for primary as well as secondary frequency regulation of microgrid however their high capital and maintenance cost is an important issue [22]. The objective of this paper is to develop the concept of grid integration of vehicle for microgrid support. Analysis is done to check the techno-economic viability of electric vehicle integration to enhance the microgrid operational efficiency. In this work smart electric vehicles are used to provide frequency regulation in place of battery storage system in a smart microgrid. The economic value of regulation service using vehicle to grid/ grid to vehicle $(\mathrm{V} 2 \mathrm{G} / \mathrm{G} 2 \mathrm{~V})$ operation of smart electric vehicles is compared with regulation provided by battery storage system.

\section{Regulation Service Using SEVs}

For an electric power system, ancillary services are important to maintain reliability of the grid while providing separate markets for electric power sale and purchase. These are also important to commensurate with the load variations of the power distribution system. In a MG system we are more concerned with regulation ancillary services. Regulation may be defined as the automatic generation control of online power resources that can respond rapidly to systemoperator requests to correct for unintended fluctuations in the power distribution system so as to comply with Control Performance Standards (CPSs). The main purpose of regulation here is to control the MG frequency and voltage to the reference levels [23]. In a MG, primary as well as secondary frequency regulation is provided by battery storage system and/or load shedding or demand response techniques (in SMGs). Large EV penetration in a MG system as a dumb load may cause higher peak demand, feeder congestion or undue overloading of the transformers leading to unbalance situations. An electric vehicle control strategy is designed and proposed here to enable electric vehicle to provide regulation-up (V2G) and regulation-down (G2V) service in response to the MG transient situations. Electric 
vehicle equipped with this controller will operate as a 'smart electric vehicle'.

The electricity from grid integration of vehicle (GIV) is costly when compared to electricity from large power plants but it can provide ancillary services like peak load shaving, regulation services, spinning reserves, etc in a power distribution market. National household travel survey [24] suggests that EVs are parked for more than $90 \%$ of the time. For this reason the fleets of EV can become a potential source of power to the microgrid without compromising on their driving schedule. Figure 1 represents the basic architecture of a MG system with smart electric vehicle, renewable (PV generator and wind turbine) and non-renewable (single shaft microturbine, SSMT) resources. There is a MG central controller (MGCC) responsible for microgrid control and power balance. Smart electric vehicle controller (SEV C) checks and controls the EV operation while plugged into the distribution circuit.

\section{Smart Electric Vehicle Operation}

SEVs incorporate a vehicle controller which operates in dual-mode i.e., $\mathrm{V} 2 \mathrm{G}$ and $\mathrm{G} 2 \mathrm{~V}$ mode. In the former operation mode, SEV injects electric power to the grid and in the latter operation it consumes electric power from the grid to charge its battery. The charging/discharging control can be performed through power- frequency droop control strategy as shown in Fig. 2. The droop constants can be fixed or adjustable. According to adjustable droop principle the droop constants are periodically modified with respect to the operating points of the distributed generator, which in this case is an active load (SEV). With this technique DG shares power according to their operational reserves, however in fixed droop control the droop constants are fixed parameters and the load demand is shared among DGs in proportion to their capacities. In this work fixed droop principle is adopted with the inclusion of battery state of charge (SOC) in it. A phase-locked loop is used to measure frequency deviations at each EV grid interface. The dead-band and slope of the frequency droop determines the operational parameters of EV and may be decided by the vehicle owner or MG operator depending upon the MG frequency regulation system requirement. The controller initiates charging (G2V mode) or discharging (V2G mode) actions whenever the frequency deviation is more than the frequency dead band and the slope of the frequency droop characteristic

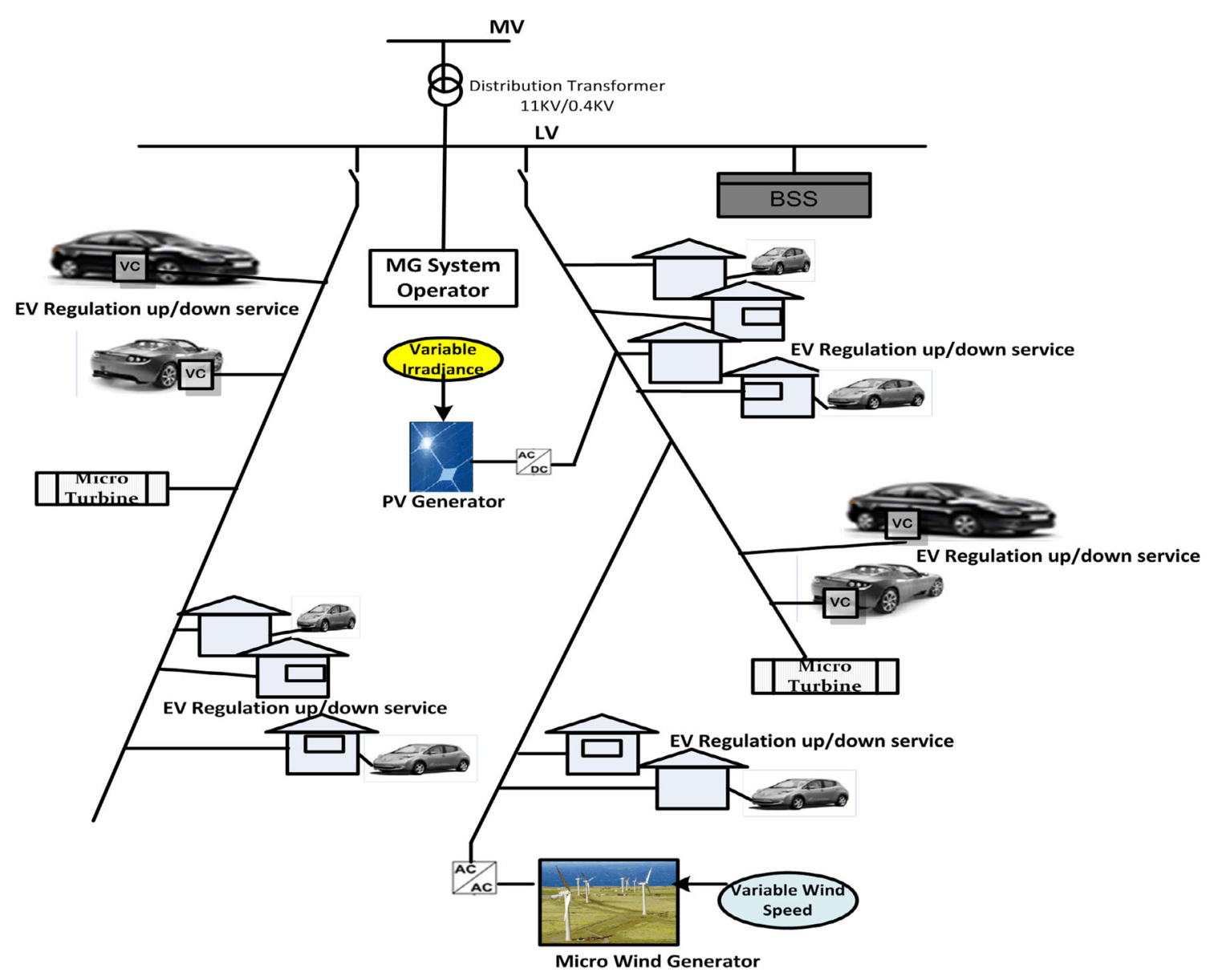

Fig. 1 MG System with BSS and SEVs 

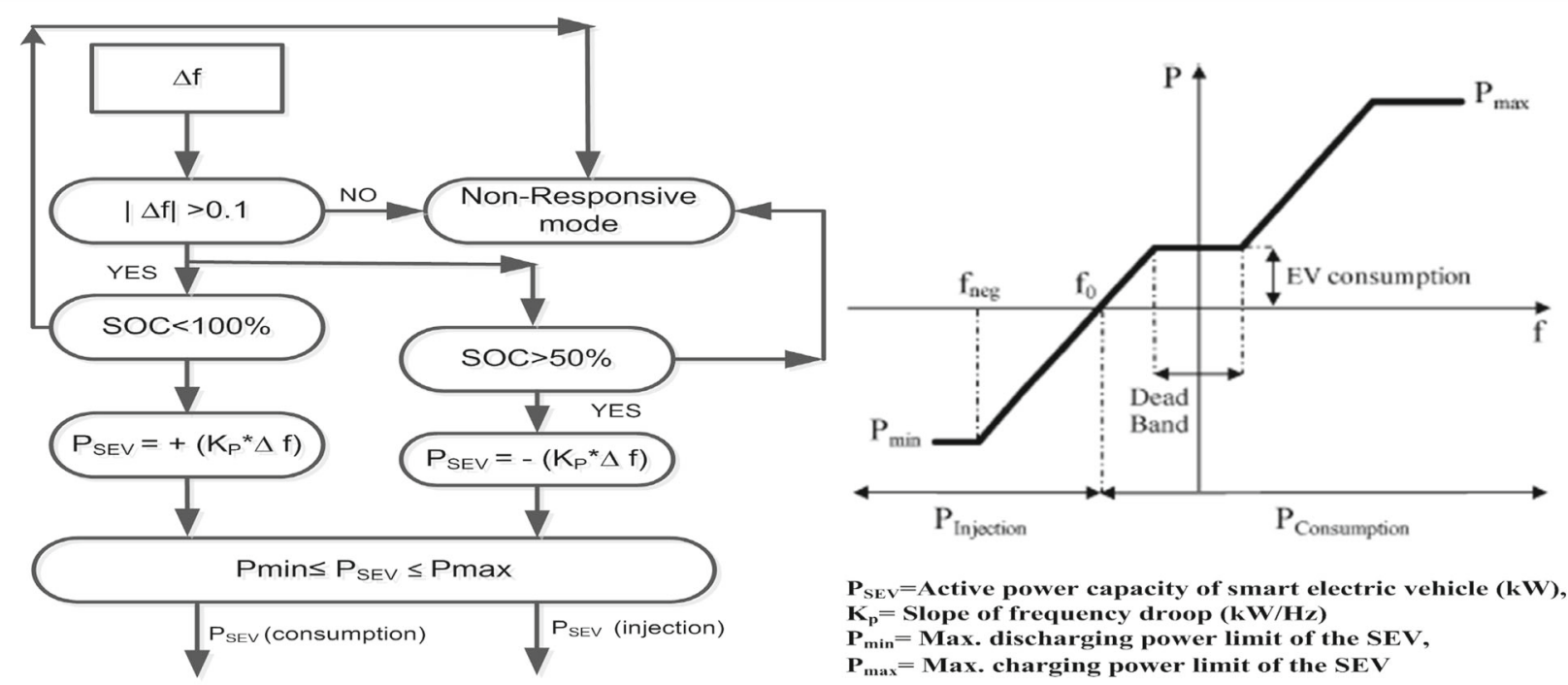

$P_{\text {SEV }}=$ Active power capacity of smart electric vehicle $(\mathbf{k W})$, $K_{p}=$ Slope of frequency droop $(\mathrm{kW} / \mathrm{Hz})$

$P_{\min }=$ Max. discharging power limit of the SEV,

$P_{\max }=$ Max. charging power limit of the SEV

Fig. 2 Smart Electric Vehicle Controller with p-f droop

decides the rate of charging and discharging of vehicle. In case of generation shortfall or high power demand, frequency of the system drops below the reference level. As soon as the frequency deviation crosses vehicle controller lower set point, vehicles with state of charge higher than $50 \%$ participate in power injection (V2G mode). This provides frequency regulation-up service. In case of excessive power generation or low power demand in the MG, frequency increase above the specified levels of vehicle controller and SEVs with SOC less than $100 \%$ move in G2V mode where controller initiates charging action and regulation-down service is aided.

\section{Proposed Frequency Regulation of MG with SEV}

MG generation and load demand unbalance cause frequency deviations and requires regulation service to restore stability and autonomous operation. MG frequency control strategy shown in Fig. 3 can provide adequate framework to exploit the EV controllability in smart MG environment. Vehicle controller is integrated to form a frequency control loop. Disturbances in MV network, sudden changes in the MG non-controllable resources (due to sudden change in wind speed and irradiance level) or sudden change in the amount of load connected to the MG result in frequency deviation, $\Delta \mathrm{f}$ and power imbalance $\Delta \mathrm{P}$, as shown in Eq. 1 .

$$
\Delta P=P_{S S M T}+P_{P V}+P_{W T} \pm P_{S E V} \pm P_{\text {grid }}-P_{L}
$$

$\mathrm{P}_{\text {SSMT }}$ is the power output of SSMTs, $\mathrm{P}_{\mathrm{PV}}$ is the power output of solar generator, $\mathrm{P}_{\mathrm{WT}}$ is the power output of micro wind generator, $\mathrm{P}_{\text {grid }}$ is the power import or export with the main grid and $\mathrm{P}_{\mathrm{L}}$ is the load connected to the MG. Energy imbalance of the MG, for a specified period of time is denoted by $E$. $T_{\mathrm{dP}}$ is the time delay due to response of voltage source inverter and $T_{i n v}$ is the time delay of SEV grid interface inverter. $\Delta \mathrm{P}$ gives rise to frequency deviation $\Delta \mathrm{f}$ and for this kind of situation emergency regulation action of SEV is initiated through vehicle controllers to provide frequency regulation for the MG transient situation.

\section{Cost Calculation for MG Regulation Service}

The economic potential of regulation service with the EV depends critically on the cost, MG utility owner is required to pay for regulation up and regulation down power to the vehicle owner. Electric vehicle is privately owned resource, therefore MG utility purchases the regulation power from EV owners and the payments are made on the basis of regulation contract, which is comprised of two components (i) contract payment of availability and (ii) energy payment per $\mathrm{kWh}$ when power is supplied. The charges for providing regulation up and down may be different or same. Equations 2-4 give the revenue paid by the utility to EV owner for providing regulation up and regulation down service respectively. For a particular MG situation total cost for regulation-up will depend upon the contract to dispatch ratio.

$R_{\text {reg-up }}=P_{\text {cap }} H_{d i s p} P_{v e h}+P_{e l} H_{d i s p} P_{v e h} R_{d-c}$

$R_{\text {reg-down }}=P_{\text {cap }} H_{\text {disp }} P_{\text {veh }}$

$R_{d-c}=\frac{E_{d i s p}}{P_{v e h} H_{d i s p}}$ 
Fig. 3 MG Frequency

Regulation scheme using SEV

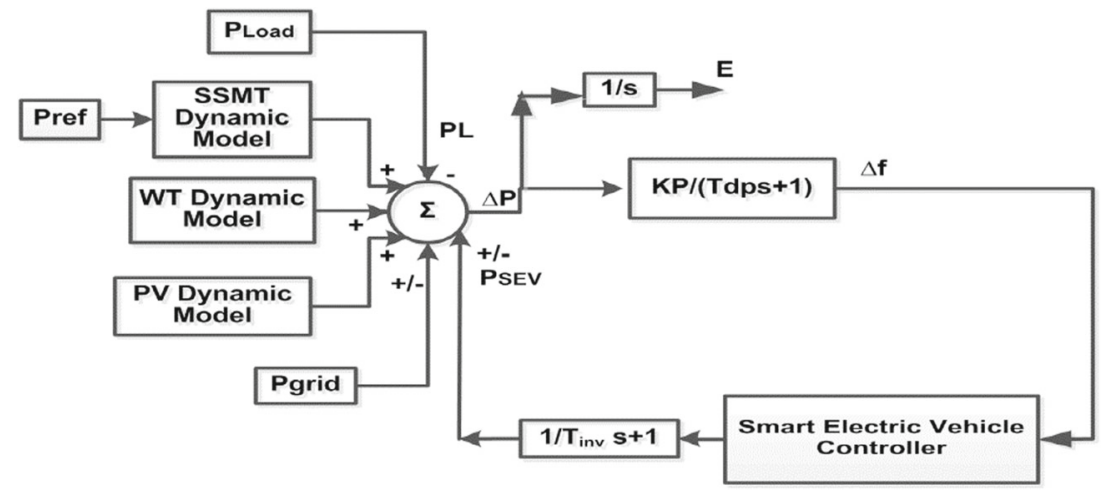

Simulation Results and Evaluation of Regulation Services

To access the viability of V2G power for grid support, different scenarios with microgrid generation variations are simulated in a test network. A residential distribution circuit is designed and simulated in MATLAB Simulink as the case study platform [25]. It is a 500kVA, $11 / 0.433 \mathrm{kV}$ LV microgrid system, Fig. 4, which can operate autonomously as well as connected to the grid. The network has four radial feeders with distributed generators like solar photovoltaic (PV) generator, a micro-wind generator and two single shaft micro turbines. Microgrid central controller (MGCC) monitors and controls the MG stability. Most of the loads operating in the MG are household loads. The loads also comprise of electric vehicles which connect to the network throughout single phase chargers for charging purpose as well as to provide power injection and regulation service. An average number of vehicles in Indian urban household is 1.3 [26], therefore for 96 houses present in the microgrid a fleet of 125 vehicles, charging at recommended rate, is considered in this study. The description of the electric vehicle considered is presented in Table 1.

The MG test system also has a battery storage system, the capacity of which is varied from 50kVA to 300kVA to simulate different MG situations and therefore the converter power for every simulation is different. MG is operated with $271 \mathrm{~kW}$ of average load. The total generation from different sources of MG is varied from $50 \mathrm{~kW}-500 \mathrm{~kW}$ to analyze the effectiveness of SEVs operation for microgrid frequency regulation.

\section{Results and Technical Analysis}

Frequency regulation is provided separately using the BSS and then GIV. The simulation results presented in Fig. 5a shows that frequency regulation is provided by BSS when frequency deviation of more than $0.9 \mathrm{~Hz}$ is seen for excessive decrease in MG generation. The results for regulation service by BSS for average increase in MG generation from system (Eqs. 5-9) for a microgrid. 


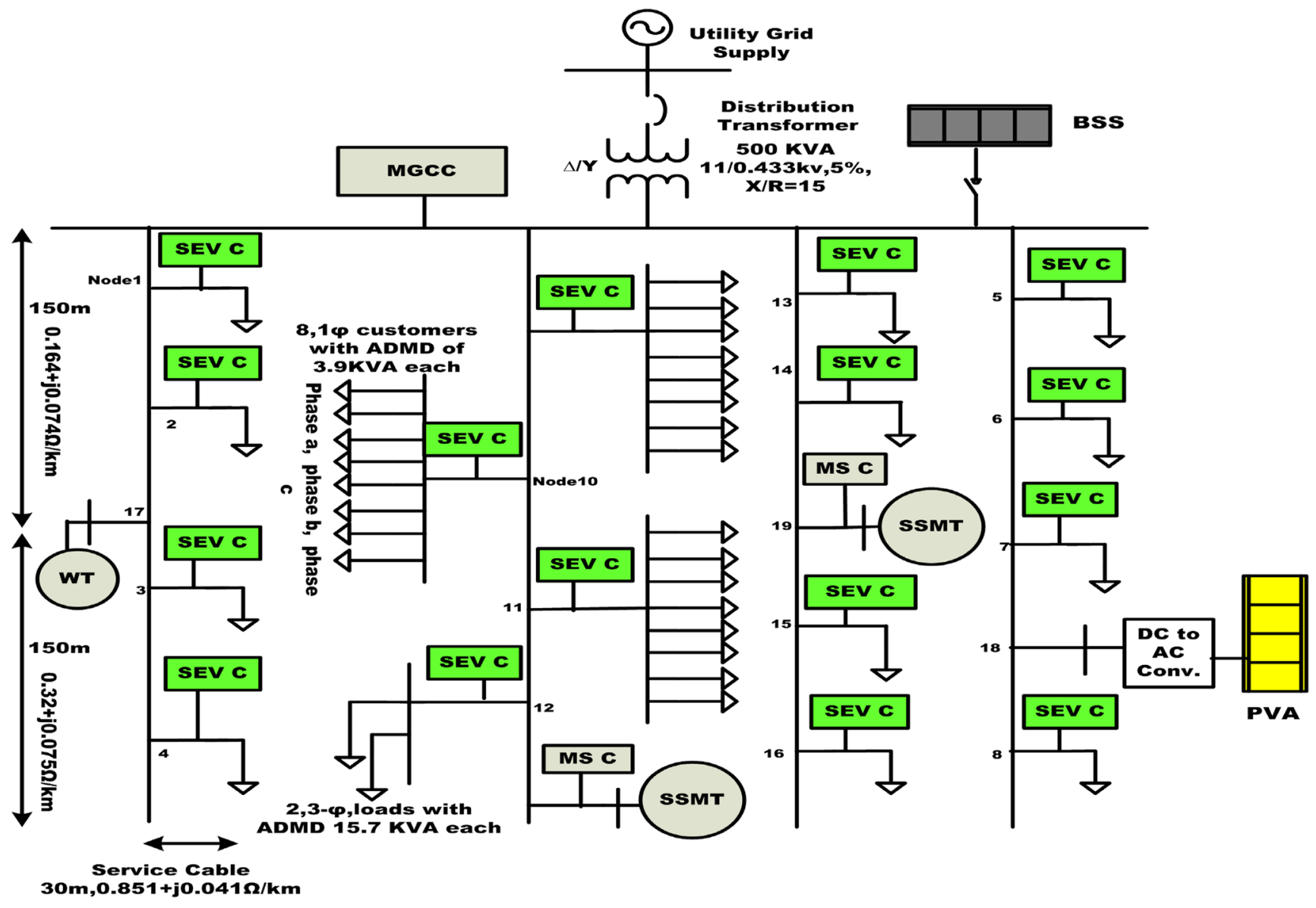

Fig. 4 MG Test System

$271 \mathrm{~kW}$ to $310 \mathrm{~kW}$ are shown in Fig. $5 \mathrm{~b}$. Figure 6 illustrates the frequency regulation of MG with SEVs. In case of sudden decrease in MG generation from $271 \mathrm{~kW}$ to $50 \mathrm{~kW}$, Fig. 6a, frequency stabilizes from $49.5 \mathrm{~Hz}$ to $50 \mathrm{~Hz}$ when regulation is provided by GIV. For this situation, $54.4 \%$ of SEVs move into V2G mode for providing MG frequency regulation with $40 \%$ SEVs which were initially in G2V mode either went into non-responsive mode or V2G mode depending upon their SOC. However in $6 \mathrm{~b}$, with increase in $\mathrm{MG}$ generation from $271 \mathrm{~kW}$ to $350 \mathrm{~kW}, 19.2 \% \mathrm{SEVs}$ adopt $\mathrm{G} 2 \mathrm{~V}$ mode to provide frequency regulation. Results for different MG situations are tabulated in Table II, to carry out the economic analysis. It can be seen that in scenarios 1-5, power generation of the MG is less than the average load of the system hence frequency deviates below the reference level contrary to scenarios 6-10 which results in frequency deviation above the reference level. For frequency regulation using BSS, the BSS capacity is changed between 50kVA to $300 \mathrm{kVA}$ for regulation-up or regulationdown until the frequency reaches the reference value. For different MG situations different levels of GIV helps in stabilizing MG frequency by operating in $\mathrm{V} 2 \mathrm{G}$ or $\mathrm{G} 2 \mathrm{~V}$ mode. As shown in Table 2, GIV may change from $54.4 \%$ to $7.3 \%$ to provide frequency regulation in a MG with average load of $271 \mathrm{~kW}$ and varying generation. It can also be observed from the simulation results that although the regulation with BSS is faster as compared to GIV but it has higher frequency fluctuations and the frequency regulation with GIV is smooth and seamless. This is because of the reason that SEVs are equipped with more advanced and sensitive controller.

\section{Results and Economic Analysis}

The cost of BSS regulation service is calculated using Eqs. 5-9. The battery cost has two components i.e., energy

Table 1 EV Specifications

\begin{tabular}{lllll}
\hline EV & Battery size & Energy available & All Electric range & Charger Power \\
\hline Nissan LEAF & $24 \mathrm{kWh}$ & $19.2 \mathrm{KWh}$ & $100 \mathrm{mi}, \mathrm{LA} 4$ mode & $3.3 \mathrm{~kW}$ (recommended) \\
\hline
\end{tabular}


Fig. 5 Frequency Regulation with BSS, (a) excessive decrease in MG Power Generation (b) average increase in MG Power Generation
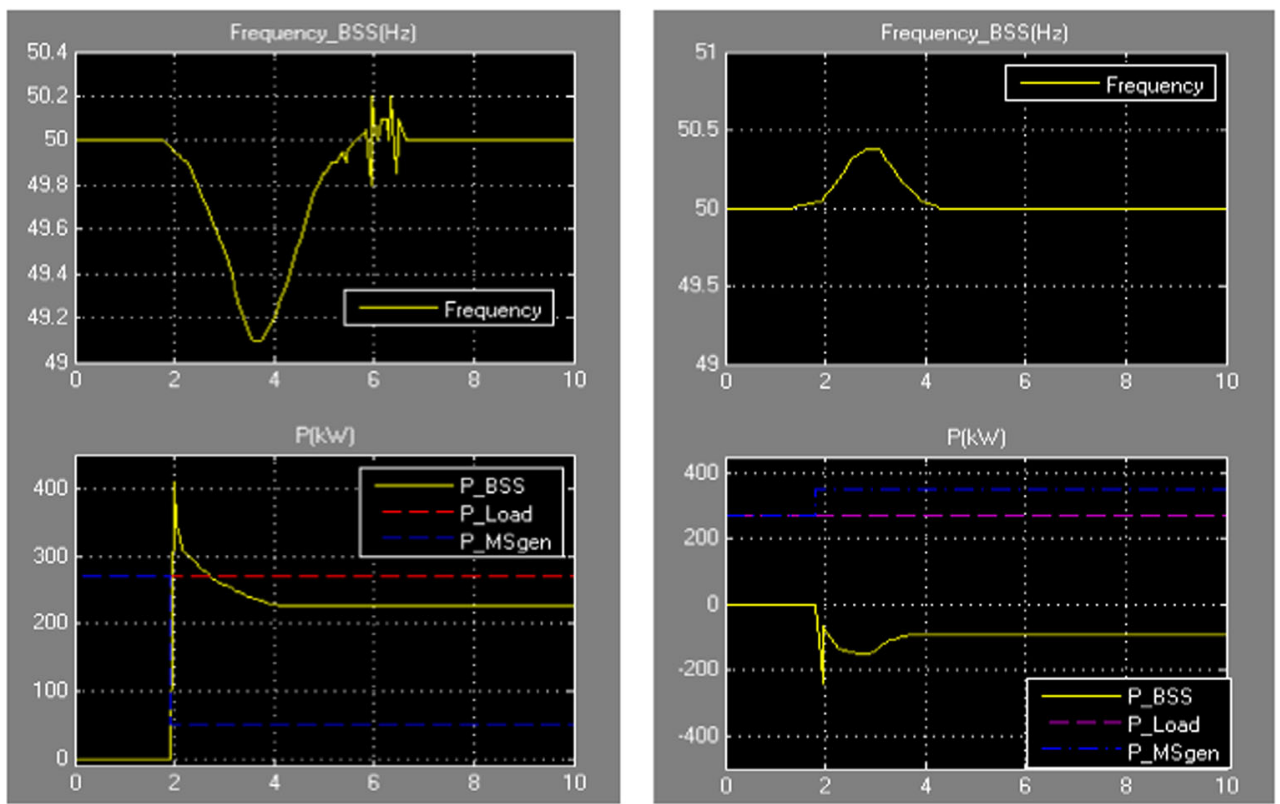

cost component and capital cost component. The capital cost of battery is annualized for the discount rate of 10 $\%$ and the investment is assumed to be amortized for a period of 10 years. The battery degradation, maintenance and replacement costs are also included in total cost calculation. For regulation service, cycling regime will be most of the time shallow type, therefore battery degradation cost here will be lower. Cost of regulation with SEVs is calculated using Eqs. 2-4. This cost is actually the revenue which MG utility has to pay to the SEV owners involved in regulation service. It includes the capacity price paid for the energy available for frequency regulation service and price paid for the unit supplied in real time. There is a MG system operator responsible for power exchange agreements. The dispatch to contract ratio, $\mathrm{R}_{\mathrm{d}-\mathrm{c}}$ for GIV is taken here as 0.9 , considering that the participant adheres to contract terms. The capacity price is assumed to be fixed at $\$ 0.004 / \mathrm{kWh}^{-1}$ and for different MG scenarios considered
Fig. 6 Frequency Regulation with GIV, (a) excessive decrease in MG Power Generation (b) average increase in MG Power Generation
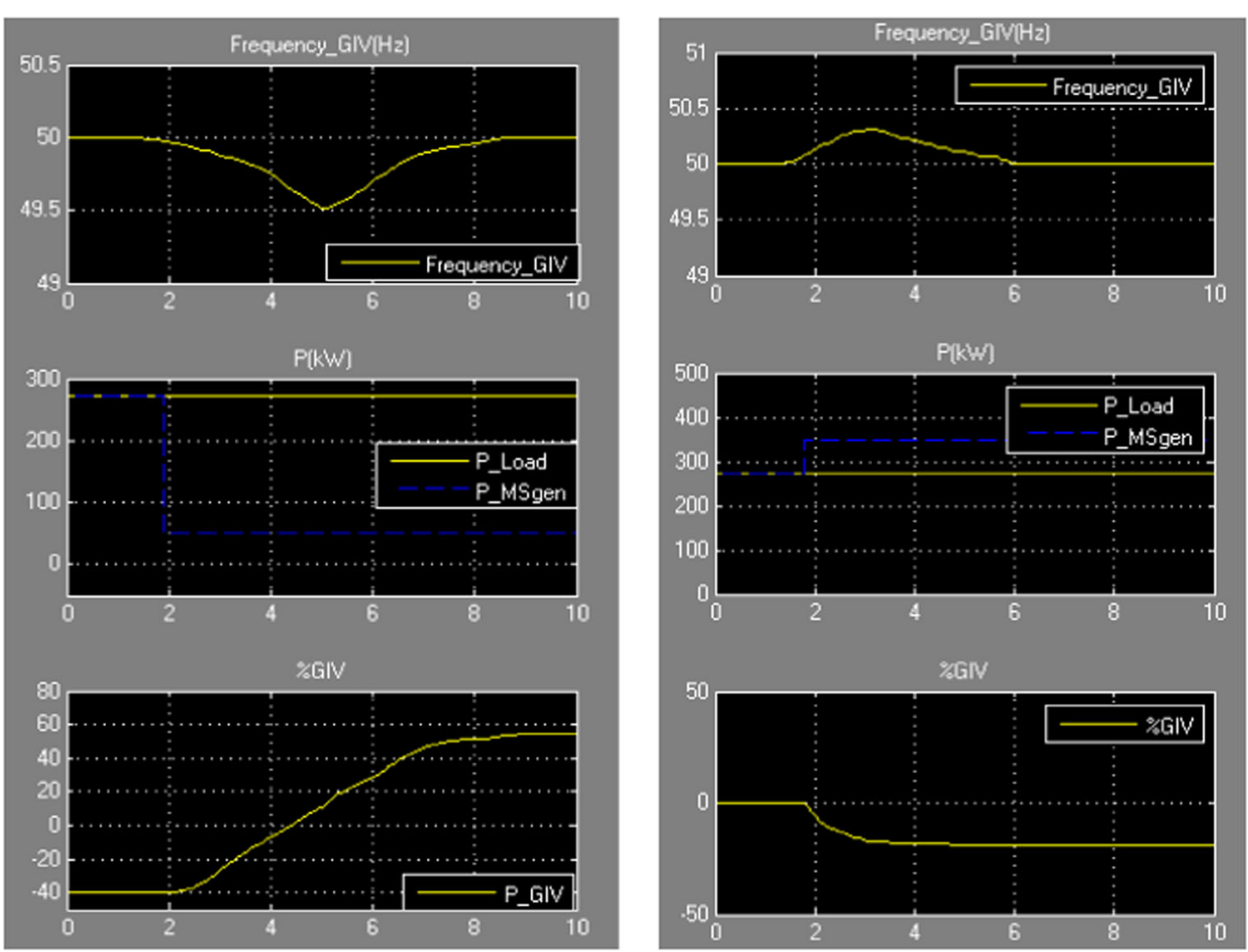
Table 2 Simulation Results for Frequency Regulation under different MG Generation Levels

\begin{tabular}{ccccl}
\hline $\begin{array}{c}\text { Scenarios Average MG } \\
\text { Generation (kW) }\end{array}$ & \multicolumn{2}{l}{$\begin{array}{l}\text { BSS Capacity GIV (\%) } \\
\text { Regulation } \\
\text { Service Type }\end{array}$} \\
\hline & 50 & 300 & 54.4 & Regulation-up \\
2 & 100 & 240 & 43.2 & \\
3 & 150 & 180 & 31.2 & \\
4 & 200 & 120 & 19.2 & \\
5 & 250 & 50 & 7.3 & \\
6 & 300 & 50 & 7.3 & Regulation-down \\
7 & 350 & 120 & 19.2 & \\
8 & 400 & 180 & 31.2 & \\
9 & 450 & 240 & 43.2 & \\
10 & 500 & 300 & 54.4 & \\
\hline
\end{tabular}

Table 3 Distribution System Regulation Price

\begin{tabular}{lll}
\hline Year & $\begin{array}{l}\text { Regulation Price } \\
(\text { Rs/KWh })\end{array}$ & $\begin{array}{l}\text { Regulation Price } \\
(\text { US \$/KWh })\end{array}$ \\
\hline $2008-09$ & 6.70 & 0.101 \\
$2009-10$ & 4.62 & 0.069 \\
$2010-11$ & 3.91 & 0.059 \\
$2011-12$ & 4.09 & 0.062 \\
$2012-13$ & 3.86 & 0.058 \\
$2013-14$ & 2.05 & 0.031 \\
\hline
\end{tabular}

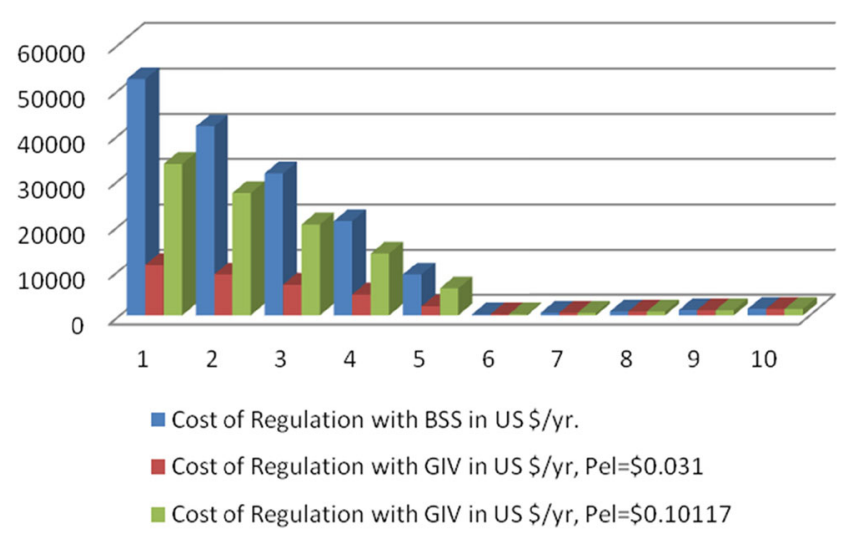

Fig. 7 Comparison of the Cost of Regulation with BSS and GIV for different MG Scenarios

in this study, 4 hours of dispatch time is observed. The regulation prices for consecutive six years are obtained from ISO [27] and represented in Table 3. The analysis is done for Indian system but for the convenience of international readers, the cost figures are approximated to US dollars at the rate of Rs $66.21 / \mathrm{US}$ \$. The cost of regulation with GIV is calculated with minimum and maximum regulation prices of the system. Results obtained after calculating cost/year of regulation using BSS and GIV are presented in Table 4. The values of different constants used for economic analysis are presented in Table 5 at appendix. The results reveal that in a MG system, GIV for frequency regulation is cost effective. It is observed that for different scenarios of MG generation and load imbalance, GIV provides the average annual saving of more than $75 \% \& 30 \%$ for higher regulation price $\&$ lower regulation price respectively as

Table 4 Comparison of Regulation Service cost using BSS and GIV with minimum and maximum Regulation Price

\begin{tabular}{|c|c|c|c|c|c|c|}
\hline Scenarios & $\begin{array}{l}\text { Cost of Regulation } \\
\text { with BSS } \\
\text { in US \$/yr. }\end{array}$ & $\begin{array}{l}\text { Cost of Regulation } \\
\text { with GIV in US } \\
\$ / y r \text { Pel=\$0.031 }\end{array}$ & $\begin{array}{l}\text { Savings with lowest } \\
\text { regulation price }\end{array}$ & $\begin{array}{l}\text { Cost of Regulation } \\
\text { with GIV in US } \\
\$ / y r \text { Pel }=\$ 0.10117\end{array}$ & $\begin{array}{l}\text { Savings with } \\
\text { highest regulation } \\
\text { price }\end{array}$ & $\begin{array}{l}\text { Type of Regulation } \\
\text { Service }\end{array}$ \\
\hline 1 & $52,243.58$ & $11,219.68$ & $78.52 \%$ & $33,431.47$ & $36.01 \%$ & Regulation-Up \\
\hline 2 & $41,794.87$ & $9,067.96$ & $78.30 \%$ & $27,019.96$ & $35.35 \%$ & \\
\hline 3 & $31,346.15$ & $6,762.54$ & $78.43 \%$ & $20,150.48$ & $35.72 \%$ & \\
\hline 4 & $20,897.43$ & $4,610.83$ & $77.94 \%$ & $13,738.96$ & $34.26 \%$ & \\
\hline 5 & $9,045.50$ & $1,998.02$ & $77.91 \%$ & $5,953.55$ & $34.18 \%$ & \\
\hline 6 & 241.6 & 231.264 & $4.28 \%$ & 231.264 & $4.28 \%$ & Regulation-Down \\
\hline 7 & 579.84 & 578.16 & $0.29 \%$ & 578.16 & $0.29 \%$ & \\
\hline 8 & 869.76 & 847.968 & $2.51 \%$ & 847.968 & $2.51 \%$ & \\
\hline 9 & $1,159.68$ & $1,137.05$ & $1.95 \%$ & $1,137.05$ & $1.95 \%$ & \\
\hline 10 & $1,449.60$ & $1,406.86$ & $2.95 \%$ & $1,406.86$ & $2.95 \%$ & \\
\hline
\end{tabular}


compared to BSS for providing same volume of regulationup service to the MG system, Fig. 7. For regulation down service savings are not significant because it involves the capacity cost factor only. The revenue paid per year to individual owner is $\$ 19.2$ for regulation down, $\$ 153.69$ (with lower regulation price) and $\$ 457.97$ (with higher regulation price) for regulation up participation. Overall results favours GIV and it is found that not only technically but economically also GIV ensures a good replacement of costly BSS in providing regulation services for the MG system.

\section{Conclusion}

An analysis has been done to evaluate the use of electric vehicles for providing regulation in a microgrid system with intermittent power generation from distributed resources (PV array and wind turbine). Regulation service is of short duration but involves high value power market. Conventionally in microgrid systems battery storage provides these services at high rates. In smart microgrid environment an efficient regulation service can be provided using SEV. The results reveal that grid integration of electric vehicle has significant economic potential to provide regulation up and down without compromising on the driving schedule. The regulation price of the region plays an important role in deciding the cost of grid integration of vehicle. GIV optimizes the overall performance of microgrid by enabling better utilization of microgrid resources. Grid integration of vehicle greatly reduces the cost of ownership of electric vehicle and hence proves to be beneficial to the vehicle owner who receives revenue for providing regulation services without any extra expanses.

The degradation cost of electric vehicle batteries is due to charging and discharging for two different services, hence this cost has to be separated into two components i.e. the cost due to battery degradation for mobility service of the vehicle and the cost due to power regulation service. Presently the cost of battery degradation is cumulatively combined with the contract payment of availability and hence customer is paid off this cost as a part of the revenue. However the design of revenue structure for this kind of electricity generation/service can be a new research idea. Design and development of coordinated, combined BSS and GIV operation is a part of our future work, which can help the evolution of advanced distribution system with active loads. The views of consumers/agencies/experts [28, 29] regarding electric vehicle usability and consumer behaviour in future will be an important aspect of this research.

\section{Appendix}

Table 5 Constants used in Numerical Analysis

\begin{tabular}{rll}
\hline S.No. & Quantity & Value \\
\hline 1 & $\mathrm{R}_{\mathrm{d}-\mathrm{c}}$ & 0.90 \\
2 & $\mathrm{C}_{\mathrm{en}}$ & $9.6 \$ \mathrm{kWh}^{-1}$ \\
3 & $\mathrm{P}_{\text {Conv }}$ & $240,192,144,96,40 \mathrm{~kW}$ \\
4 & $\mathrm{H}_{\text {ch, }} / \mathrm{H}_{\text {disp }}$ & $4 \mathrm{hrs}$. \\
6 & $\mathrm{C}_{\mathrm{pel}}$ & $0.031 \$ \mathrm{kWh}^{-1}$ \\
7 & $\eta_{\text {conv }}$ & 0.73 \\
8 & $\mathrm{E}_{\mathrm{S}}$ & $1920,1536,1152,768,320 \mathrm{kWh}$ \\
9 & $\mathrm{C}_{\mathrm{c}}$ & $60.4 \$ \mathrm{kWh}^{-1}$ \\
10 & $\mathrm{C}_{1}$ & $7.55 \$ \mathrm{kWh}^{-1}$ \\
11 & $\mathrm{t}_{1}$ & $2 \mathrm{hrs}$. \\
12 & $\mathrm{~L}_{\mathrm{s}}$ & $10 \mathrm{yrs}$. \\
13 & $\mathrm{D}$ & $10 \%$ \\
14 & $\mathrm{~N}$ & $10 \mathrm{yrs}$. \\
15 & $\mathrm{P}_{\text {cap }}$ & $0.004 \$ \mathrm{kWh}^{-1}$ \\
16 & $\mathrm{P}_{\mathrm{el}}$ & $0.031,0.10117 \$ \mathrm{kWh}^{-1}$ \\
17 & $\mathrm{P}_{\mathrm{veh}}$ & $3.3 \mathrm{~kW}$
\end{tabular}

\section{References}

1. Meliopoulos AP, Cokkinides G, Huang SR, Farantatos E, Choi S, Lee Y, Yu X (2011) Smart Grid Technologies for Autonomous Operation and Control. IEEE Trans Smart Grid 2(1):1-9

2. Thomas MS, Macdonald JD (2015) Power System SCADA and smart grids, CRC Press, Taylor and Francis Group

3. Lasseter RH, Piagi P (2007) Extended microgrid using (DER) distributed energy resources. In: Proc. IEEE PES Gen. meeting, Tampa, FL, USA, pp 1-5

4. Hatziargyrious N (2014) Microgrids: Architectures and Control, wiley-IEEE press

5. Bae S, Kwasinski A (2012) Dynamic modeling and operation strategy for a microgrid with wind and photovoltaic resources. IEEE Trans Smart Grid 3(4):1867-75

6. Pecas Lopes JA, Moreira CL, Madureira AG (2006) Defining control strategies for microgrids islanded operation. IEEE Trans Power Syst 21(2):916-24

7. Bevrani H, Shokoohi S (2013) An Intelligent Droop control for simultaneous voltage and frequency regulation in islanded microgrids. IEEE Trans Smart Grid 4(4):1505-1513

8. Qiang F, Hamidi A, Nasiri A, Bhavaraju V (2013) The Role of Energy Storage in a Microgrid Concept: Examining the opportunities and promise of microgrids. IEEE Electrification Mag $1(2): 21-29$

9. Gouveia C, Moreira J, Moreira CL, Pecas Lopes JA (2013) Coordinating Storage and Demand response for Microgrid Emergency Operation. IEEE Trans Smart Grid 4(4):1898-1908

10. Som T, Chakraborty N (2014) Studies on Economic feasibility of an Autonomous Power delivery system utilizing alterative hybrid distributed energy resources. IEEE Trans Power Syst 29(1):172181 
11. Ahn S-J, Nam S-R, Choi J-H, Moon S-II (2013) Power scheduling of distributed generators for economic and stable operation of a microgrid. IEEE Trans Smart Grid 4(1):398-405

12. Cao Y, Tang S, Li C, Zhang P, Tan Y, Zhang Z, Li J (2012) An optimized EV charging model considering TOU price and SOC curve. IEEE Trans Smart Grid 3:388-393

13. Richardson P, Flynn D, Keane A (2012) Optimal charging of electric vehicles in low-voltage distribution systems. IEEE Trans Power Syst 27:268-279

14. Clement-Nyns C, Haesen E, Driesen J (2010) The impact of charging plug-in hybrid electric vehicles on a residential distribution grid. IEEE Trans Power Syst 25:371-380

15. Hashemi-Dezaki H, Hamzeh M, Askarian-Abyaneh H, HaeriKhiavi H (2015) Risk management of Smart Grids based on managed charging of PHEVs and vehicle-to-grid strategy using Monte Carlo simulation. Energy Convers Manag 100:262-276. doi:10.1016/j.enconman.2015.05.015

16. Tomic J, Kempton W (2007) Using the fleet of electric-drive vehicles for grid support, Journal of Power Sources, Elsevier, 1-10

17. Zhang M, Chen J (2013) The energy management and optimised operation of electric vehicles based on microgrid. IEEE Trans Power Delivery 29(3):1427-1435

18. Shao S, pipattanasomporn M, Rahman S (2012) Grid integration of EVs and demand response with customer choice. IEEE Trans Smart Grid 3(1):543-550

19. Vandael S, Kamboj S (2013) A comparison of two GIV mechanisms for providing ancillary services at university of Delaware Proceedings of the fourth IEEE international conference on smart grid communications, Vancouver, 21-24

20. Lopes JA, Soares FJ, Rocha Almeida PM (2011) Pecas Integration of electric vehicles in the electric power system. Proc IEEE 1:99

21. Kempton W, Udo V, Huber K, Komara K, Latendre S, Baker S, Bruner D, Pearre N (2009) A test of V2G for energy storage and frequency regulation in the PJM system, Report on results from an industry-university research partnership, Delaware

22. Hittinger Eric, Wiley T, Kluza J, Whitacre J (2014) Evaluating the value of batteries in MG electricity systems using an improved energy systems model, Energy conversion and management, Elsevier, pp 458-472

23. Ali Pourmousavi S, Hashem M (2012) Real-Time central Demand Response for Primary Frequency Regulation in Microgrids. IEEE Trans Smart Grid 3(4):1983-1996

24. www.unep.org/Transport/lowcarbon/Pdf's/Fuelefficiencyvehicle tech.pdf

25. Nisar A, Thomas MS (2016) Comprehensive control for microgrid autonomous operation with demand response. IEEE Trans Smart Grid 19:1-9. doi:10.1109/TSG.2016.2514483

26. Goel R, Mohan D, Guttikunda S, Tiwari G Vehicle characteristics in Indian cities - Report UNEP 23.08.2013, [online].

27. Report on short term power Market in India (2013-14) Economics Division, Central Electricity regulatory commission, India
28. Di W, Aliprantis DC, Ying L (2012) Scheduling and dispatch for aggregators of Plug-In EV. IEEE Trans Smart Grid 3(1):368-376

29. Xenias D, Axon CJ, Whitmarsh L, Connor PM, Balta-Ozkan N, Spence A (2015) UK Smart Grid development: An expert assessment of the benefits, pitfalls and functions. Renew Energy 81:89-102. doi:10.1016/j.renene.2015.03.016

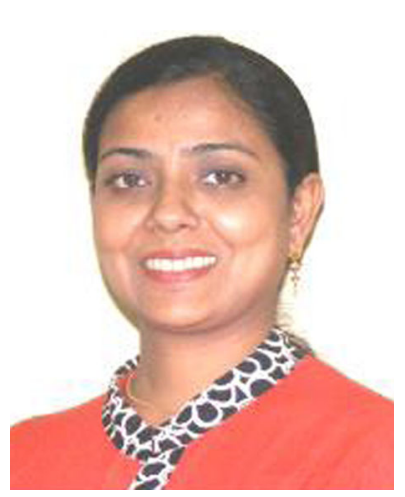

Amira Nisar Siddiqui received

B.Tech (Electrical Engg.) and M.Tech (Electrical Power System Management) from the department of Electrical Engg., JMI, New Delhi, India, where she is currently working towards the Ph.D. degree in Electrical Engg. She is Lecturer, Electrical Engg., at G. B. Pant Institute of Technology, Directorate of Training and Technical Education, New Delhi, India. Her research interests include smart grid, demand response and electric vehicles. microgrid, renewable energy,

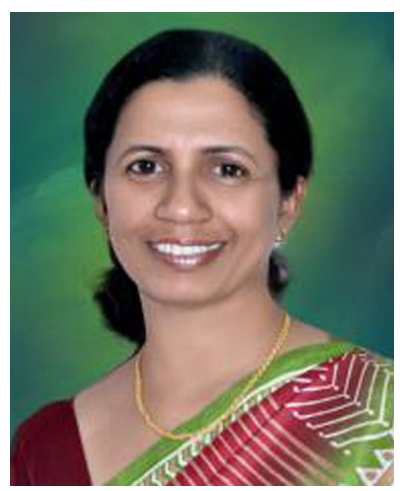

Mini Shaji Thomas is Professor in the Department of Electrical Engineering, Jamia Millia Islamia (JMI), and Director of the Centre for Innovation and Entrepreneurship at the University. Mini graduated from University of Kerala, completed her M. Tech from IIT Madras, both with gold medals and $\mathrm{PhD}$ from IIT Delhi, India. She has published around 120 research papers in International Journals and Conferences of repute, and is the coordinator of the Special Assistance Program (SAP) on Power System Automation. Mini has set up the first of its kind SCADA laboratory and Substation Automation (SA) Laboratory at JMI, and started a unique $M$ Tech program in Electrical Power System Management. Mini is a Distinguished Lecturer (DL) of IEEE Power and Energy Society and is the author of the text book; 'Power System SCADA and Smart Grid. 